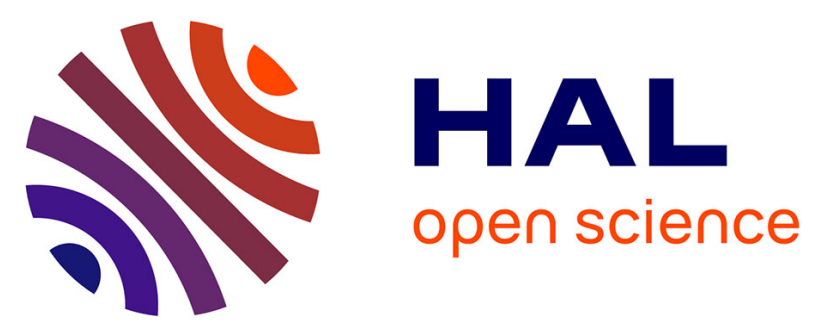

\title{
Intensive EELS study of epoxy composites reinforced by graphene-based nanofillers
}

Yu Liu, Ann-Lenaig Hamon, Benhui Fan, Delong He, Paul Haghi-Ashtiani, Thomas Reiss, Jinbo Bai

\section{- To cite this version:}

Yu Liu, Ann-Lenaig Hamon, Benhui Fan, Delong He, Paul Haghi-Ashtiani, et al.. Intensive EELS study of epoxy composites reinforced by graphene-based nanofillers. Journal of Applied Polymer Science, 2018, 135 (41), pp.46748. 10.1002/app.46748 . hal-01960226

\section{HAL Id: hal-01960226 \\ https://hal-centralesupelec.archives-ouvertes.fr/hal-01960226}

Submitted on 20 Apr 2020

HAL is a multi-disciplinary open access archive for the deposit and dissemination of scientific research documents, whether they are published or not. The documents may come from teaching and research institutions in France or abroad, or from public or private research centers.
L'archive ouverte pluridisciplinaire HAL, est destinée au dépôt et à la diffusion de documents scientifiques de niveau recherche, publiés ou non, émanant des établissements d'enseignement et de recherche français ou étrangers, des laboratoires publics ou privés. 


\section{Intensive EELS study of epoxy composites reinforced by graphene-based nanofillers}

Yu LIU, Ann-Lenaig HAMON*, Benhui FAN, Delong HE, Paul HAGHI-ASHTIANI, Thomas REISS, Jinbo BAI*

Laboratoire Mécanique des Sols, Structures et Matériaux (MSSMat), CNRS UMR 8579, CentraleSupélec, Université Paris-Saclay, 3 rue Joliot-Curie, 91192 Gif-sur-Yvette Cedex, France

Corresponding author: Jinbo BAI, (jinbo.bai@centralesupelec.fr)

\section{Ann-Lenaig HAMON, (ann-lenaig.hamon@centralesupelec.fr)}

(The TEM sample preparation procedure as Additional Supporting Information can be found in the online version of this article.)

\section{ABSTRACT}

A detailed analysis of composites with epoxy matrix and three types of graphene-based nanofillers combining scanning transmission electron microscopy (STEM) and electron energy loss spectroscopy (EELS) was reported here. The composites were prepared by a three-roll milling method and the nanofillers were well dispersed in the matrix, as confirmed by SEM and STEM observation. Mass density profiles through the interface from the matrix to the nanofillers were obtained thanks to the plasmon energy values measured from the low-loss spectra. The core-loss spectra revealed the chemical bonding states of different phase regions and identified the different chemical composition of GNPs in GNPs/epoxy and GNP-CNTs/epoxy composites. Energy dispersive spectroscopy (EDX) mapping was also conducted to further confirm the components in different phase regions. The successful characterization of the chemical structure and the bonding states paves the way for a better understanding of the structure-property relationships in composites. 


\section{INTRODUCTION}

Since reported in 2004, graphene has attracted enormous attention due to its remarkable mechanical, thermal and electrical properties, due to its unique planar structure and geometry ${ }^{1-3}$. These excellent properties provide graphene a wide range of applications in many areas, such as electronics ${ }^{4}$, energy storage and conversion ${ }^{5}$, biotechnology ${ }^{6}$, etc. Among them, polymer composites, which incorporate graphene to improve the final performance, is the most promising one ${ }^{7,8}$. However, the interaction between original graphene and the polymer matrix is very weak due to its neutral and ultra-flat surface. Therefore, a surface modification of graphene is crucial to improve its interaction with the polymer matrix and obtain high-performance composites ${ }^{9,10}$.

There are two major routes to improve the interaction between nanofillers and polymer matrix: introducing a "strong" chemical bonding ${ }^{11-14}$ and increasing the surface roughness ${ }^{15}$. Graphene oxide (GO), a representation of the first strategy, is an ideal candidate for nanofillers in composites with enhanced interface interactions and strength, due to the abundant functional groups on the surface. It results in a high efficiency of the load transfer and in improved mechanical properties. Furthermore, GO can be used as an initiator to graft other molecules for specific applications ${ }^{16}$. Khobragade et al. ${ }^{17}$ reported nano-polystyrene modified graphene oxide hybrids; after adding hybrid nanostructures, epoxy hybrid nanocomposites showed a significant variation when a lower amount of hybrid nanostructures was incorporated in an epoxy matrix.

The latter strategy, the increasing of surface roughness, is also known as a physical reinforcement. Depositing nanoparticles and grafting carbon nanotubes (CNTs) on graphitic surfaces are the most used methods. Haeri et al. ${ }^{18}$ deposited silica particles on GO surfaces through a twostep sol-gel route; the obtained $0.1 \mathrm{wt} \%$ silica-GO/epoxy composite has remarkably increased tensile strength, storage modulus, cross-linking density and glass transition temperature. Our group has achieved excellent research works on the investigation of Graphite nanoplatelets (GNP)-CNT hybrid synthesis as well as applications for sensors and electrodes ${ }^{19-21}$.

A characterization of the structure morphology is crucial to obtain an effective understanding of the structure-property relationships of the composites. Usually, a detailed information on the dispersion and exfoliate state of graphene-based nanofillers can be gained by transmission electron microscope (TEM) ${ }^{22}$. Nevertheless, both materials are mainly formed of carbon atoms, which leads to a weak contrast on the images. Furthermore, the polymer matrix is very sensitive under electron exposure. Damage may be observed after a long-time exposure to the electron beam. To overcome the above-mentioned limitations, scanning transmission electron microscopy (STEM) combined with 
electron energy-loss spectroscopy (EELS) has been intensively used in recent years. In the STEM mode, the images are acquired by moving a focused beam in a raster across the specimen and collecting a signal at each $\mathrm{x}$, y pixel coordinates. The signals for all pixels together make the STEM image. In our previous work, we used the plasmon peak in the low-loss range to measure the density of GO/epoxy and GNP/epoxy composites and successfully identify the interphase region between the nanofillers and the matrix ${ }^{23}$. Leyva-Porras et al. ${ }^{24}$ studied the functionalized GO reinforced Nylon-6 fibers by combining STEM and EELS and revealed the structures in different phases by using carbon K-edge spectra. Shin et al. ${ }^{25}$ used middle angle annual dark field imaging and EELS mapping to obtain the morphology and the thickness of the graphite platelets in composite membranes. Wu et al. ${ }^{26}$ have also successfully identified the interphase region between a carbon fiber and epoxy using EELS.

In this work, GNP-CNT hybrids are synthesized by the chemical vapor deposition (CVD) method. The three-roll milling technique is used to prepare the three types of graphene-based composites (G/epoxy composites), GNP/epoxy, GO/epoxy and GNP-CNT/epoxy, respectively. The detailed distribution state and morphology of G/epoxy will be studied by SEM and STEM, where the samples are prepared by a focused ion beam (FIB). The influence of thickness on the low-loss and the coreloss peaks is studied. The chemical component, bonding states combined with the physical density of the matrix and the nanofillers is analyzed using EELS. The results are further confirmed by energydispersive spectroscopy (EDX).

\section{EXPERIMENTAL}

\section{Sample preparation}

The GNP-CNT hybrid was produced by a CVD method. Acetylene $\left(\mathrm{C}_{2} \mathrm{H}_{2}\right)$ was used as the carbon source and ferrocene $\left(\mathrm{Fe}\left(\mathrm{C}_{5} \mathrm{H}_{5}\right)_{2}\right)$ as the catalyst precursor. A typical process can be reduced to the following steps [4]: First, the as received GNP powders (KNANO, China) were homogeneously spread on a quartz plate $\left(4 * 30 \mathrm{~cm}^{2}\right)$ using a sieve, the plate was placed in a quartz tube reactor $(120 \mathrm{~cm}$ in length, $45 \mathrm{~mm}$ in inner diameter) heated to $650 \stackrel{\circ}{\mathrm{C}}$ by a horizontal tube furnace (75 $\mathrm{cm}$ in length) under argon atmosphere. Then, the ferrocene, dissolved in xylene $\left(\mathrm{C}_{2} \mathrm{H}_{10}\right)$ at a concentration of $0.05 \mathrm{~g}$ $\mathrm{cm}^{-1}$, was injected into the reactor by a syringe system and carried to the stable reaction zone in the form of a spray by carrier gases $\left(\mathrm{Ar}\right.$ and $\mathrm{H}_{2}$ ). Accompanying the injection of the catalyst solution, acetylene was also fed into the reactor simultaneously. The gas flow rate was controlled by electronic mass flow meters (Bronkhorst). The CNT growth time was set to $15 \mathrm{~min}$. After growth, the system was cooled down to room temperature under argon atmosphere.

Epoxy resin (1080S) and curing agent (1084) were purchased from Resoltech Ltd., France. The procedure for preparing $4.0 \mathrm{wt} . \% \mathrm{GNP} / \mathrm{epoxy}$ composites is as follows: $0.8 \mathrm{~g}$ nanofiller was mixed 
with $14.4 \mathrm{~g}$ of epoxy resin by a three-roll mill (EXAKT 80, Germany) for $30 \mathrm{~min}$. The gap size between the adjacent rollers was set to $50 \mu \mathrm{m}$ and the rotation speed was set to $30 \mathrm{rpm}$. Afterwards, $4.8 \mathrm{~g}$ of curing agent were manually mixed with the previous sample to obtain a homogeneous suspension. The mixture was poured into an aluminum bowl and had a thickness of $5 \mathrm{~mm}$. Then, the sample was degassed for $60 \mathrm{~min}$ at room temperature in a vacuum oven. After that, the mold was put in an oven at $60^{\circ} \mathrm{C}$ for $15 \mathrm{~h}$. Due to our previous work, after $15 \mathrm{~h}$ at $60^{\circ} \mathrm{C}$, the crosslinking was still unfinished, so the sample was annealed at $100^{\circ} \mathrm{C}$ for $1.5 \mathrm{~h}$ to complete the crosslinking reaction. The same procedure was applied on GO (Standard Graphene, Korea)/epoxy and GNP-CNT/epoxy composites.

\section{Characterization}

A SEM (LEO 1530 Gemini) was used to characterize the GNP morphology and the composite fracture surface. The cross-section of the sample was prepared by immersing the thin composite sample in liquid nitrogen for $10 \mathrm{~min}$ and then by breaking it. TEM imaging was performed using a TITAN ${ }^{3}$ G2 60-300 (FEI) operating at an accelerating voltage of 80kV. EELS tests were carried out in STEM mode, with an electron probe diameter around $130 \mathrm{pm}$. The EELS energy resolution was $1 \mathrm{eV}$. Digital images and energy-loss spectra were captured using a Gatan imaging filter with a dispersion of $0.1 \mathrm{eV} /$ channel for 0 -loss spectra and low-loss spectra, $0.25 \mathrm{eV} /$ channel for core-loss spectra, respectively. The spectral background was removed using a power law function. The convergence and collection semi-angles were 17.9 and $14.5 \mathrm{mrad}$, respectively. Further spectral processing was conducted using the Gatan digital micrograph (DM) software. The elemental composition and mapping were conducted via local chemical analysis performed using STEM-EDX with a high angular annular dark field (HAADF) detector in TEM. The sample thickness in different regions, $\mathbf{t}$, was obtained from energy-loss spectra using the log-ratio method ${ }^{27}$. The inelastic mean free path was calculated using the method of lakoubovskii et al. ${ }^{28}$. The density of the pure epoxy matrix measured by the traditional weight-volume method is $1.13 \mathrm{~g} / \mathrm{cm}^{3}$.

\section{RESULTS AND DISCUSSION}



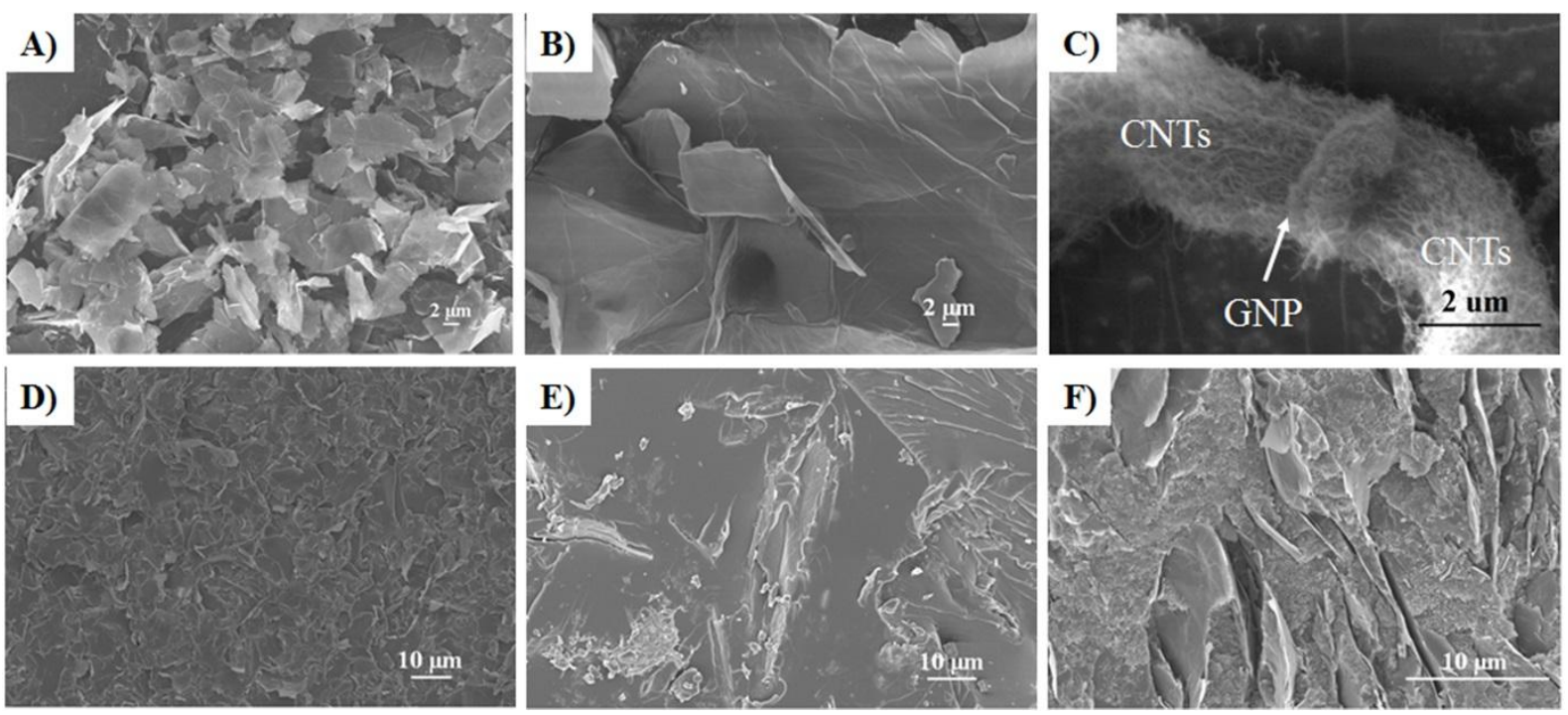

Figure 1 SEM images of (A) GNPs, (B) GO and (C) GNP-CNT hybrid; Fracture surfaces of G/epoxy composites with a fraction of 4wt\%, (D) GNP/epoxy, (E) GO/epoxy and (F) GNP-CNT/epoxy, respectively.

The structures of the nanofillers are shown in Figure 1. The GNPs have a diametric distribution of 5-10 $\mu \mathrm{m}$ with a thickness of $5 \mathrm{~nm}$. These platelets are semitransparent when observed in SEM (Figure 1A). However, GOs in Figure 1B are much larger laterally compared with GNPs. Based on the supplier's information, the lateral size of GOs are around $7 \mu \mathrm{m}$. The much larger lateral size observed by SEM could possibly be attributed to the aggregation during the drying process. Figure $1 \mathrm{C}$ shows the successful synthesis of GNP-CNT hybrids. It is noteworthy that all CNT clusters were observed as grown perpendicularly with aspect to the surface of the GNPs. The diameter range of the CNTs goes from 50 to $80 \mathrm{~nm}$ and the length is in the range of several tens of micrometers.

Figure 1D-F show the cross-section of G/epoxy composites. After mixing by the three-roll milling method, the nanofillers are homogeneously distributed in the matrix. In Figure 1D, some GNPs are pulled out directly from the epoxy matrix with a smooth surface, which infers the weak interfacial connection between the original GNPs and the matrix. Since the sample was prepared by brittle fracture in liquid $\mathrm{N}_{2}$, the weak interface may have already been separated during this process, which leads to the appearance of cracks between the GNPs and the epoxy in the image. After oxidation, the GO surface has introduced many types of oxygen-containing groups, such as hydroxyl, carboxyl and epoxy ${ }^{29,30}$. These groups can participate in the crosslinking reaction during the curing process, which leads to a stronger interface. However, the three-roll milling process cannot exfoliate the aggregated GOs. Hence, the separation can happen at the interlayers during the break. In Figure $1 E$, some traces with wrinkled surfaces of GOs appear. Figure $1 \mathrm{~F}$ shows the SEM morphology of the 
fracture surface of GNP-CNTs/epoxy, where GNP-CNTs are well immersed in the epoxy matrix without aggregation due to the existence of the perpendicularly grown CNTs. The coupling of 1D-2D structures displays the maximum effective surface, leading to a largely increased interfacial adhesion.

TEM and STEM investigations were performed on the composite films prepared by FIB. Since the nanofillers and the matrix have similar elemental components, the HAADF detector in STEM mode was used, with two benefits. First, small differences in the average atomic number or thickness of the material could be identified with a higher contrast difference in the dark field images. Secondly, the electron beam could be focused on a very small disk around $150 \mathrm{pm}$ in diameter in order to have a local analysis in STEM mode ${ }^{31}$. Figure 2(A-C) shows HAADF-STEM images for different G/epoxy composite films. For the GNP/epoxy composite in Figure $\mathbf{2 A}$, the GNPs could be easily recognized with their whiter contrast, which is due to the larger thickness compared to the surrounding matrix. Since GNPs have a much higher hardness than the epoxy matrix, the GNP part and the matrix part cannot reach the same thickness at the same milling conditions. What more, the upper side of the images is darker than the bottom, which is also caused by a small difference in thickness. Figure 2B shows a GO/epoxy composite. Though less contrast exists between $\mathrm{GO}$ and matrix, the $\mathrm{GO}$ is clearly distinguished in the central part with a thickness of several hundred of nanometers. The interface between the GO and matrix is rougher than that of GNP and matrix. The traces on the surface are due to the milling process. There is also a small different contrast in the matrix part due to the thickness variation. Figure $\mathbf{2 C}$ demonstrates a GNP-CNT/epoxy composite, the GNP having a platelet shape on the right side, the grafted CNTs are well dispersed in the surrounding matrix.

In three HAADF-STEM images, the thickness is measured at three different spots, and the values are listed in Figure 2(D-F). In the GNP/epoxy sample, 5 positions are marked out in the epoxy matrix, where low-loss and core-loss spectra were acquired. The $\ln \left(\mathrm{I}_{\mathrm{t}} / \mathrm{l}_{0}\right)$ values are calculated by the DM software. The inelastic MFP of the matrix is calculated as $113 \mathrm{~nm}$. For all test position in the epoxy matrix, the thickness is lower than the inelastic MFP, and the thickness even reaches $50 \mathrm{~nm}$ at some point. 6 positions are marked out in the GO/epoxy sample, in which points 4 and 5 are in the GO region, the others being in the epoxy matrix. All the thicknesses are lower than $100 \mathrm{~nm}$. In the GNPCNT/epoxy sample, the thickness is greater than with the two other samples and is around $110 \mathrm{~nm}$. 

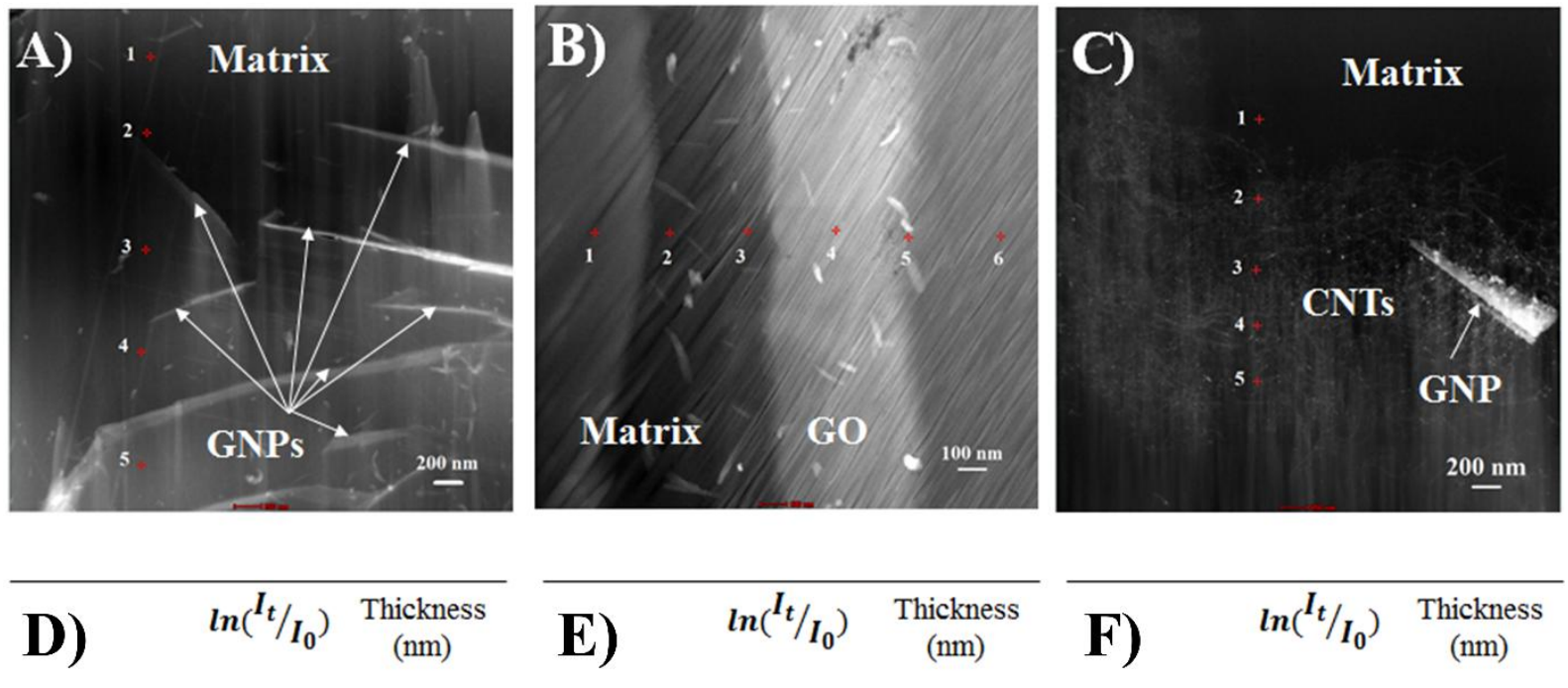

\begin{tabular}{ccc}
1 & 0,71 & 80 \\
2 & 0,45 & 50 \\
3 & 0,57 & 64 \\
4 & 0,75 & 84 \\
5 & 1,00 & 112 \\
\hline
\end{tabular}

$\begin{array}{ccc}1 & 0,69 & 77 \\ 2 & 0,60 & 67 \\ 3 & 0,83 & 93 \\ 4 & 0,6 & -- \\ 5 & 0,67 & -- \\ 6 & 0,79 & 89\end{array}$

$\begin{array}{ccc}1 & 1,02 & 115 \\ 2 & 0,94 & -- \\ 3 & 0,99 & -- \\ 4 & 1,18 & -- \\ 5 & 1,28 & --\end{array}$

Figure 2 HAADF-STEM images of (A) GNP/epoxy, (B) GO/epoxy and (C) GNP-CNT/epoxy composites; Tables D-F show thickness values of each point measured in several areas on images (A)-(C), respectively.
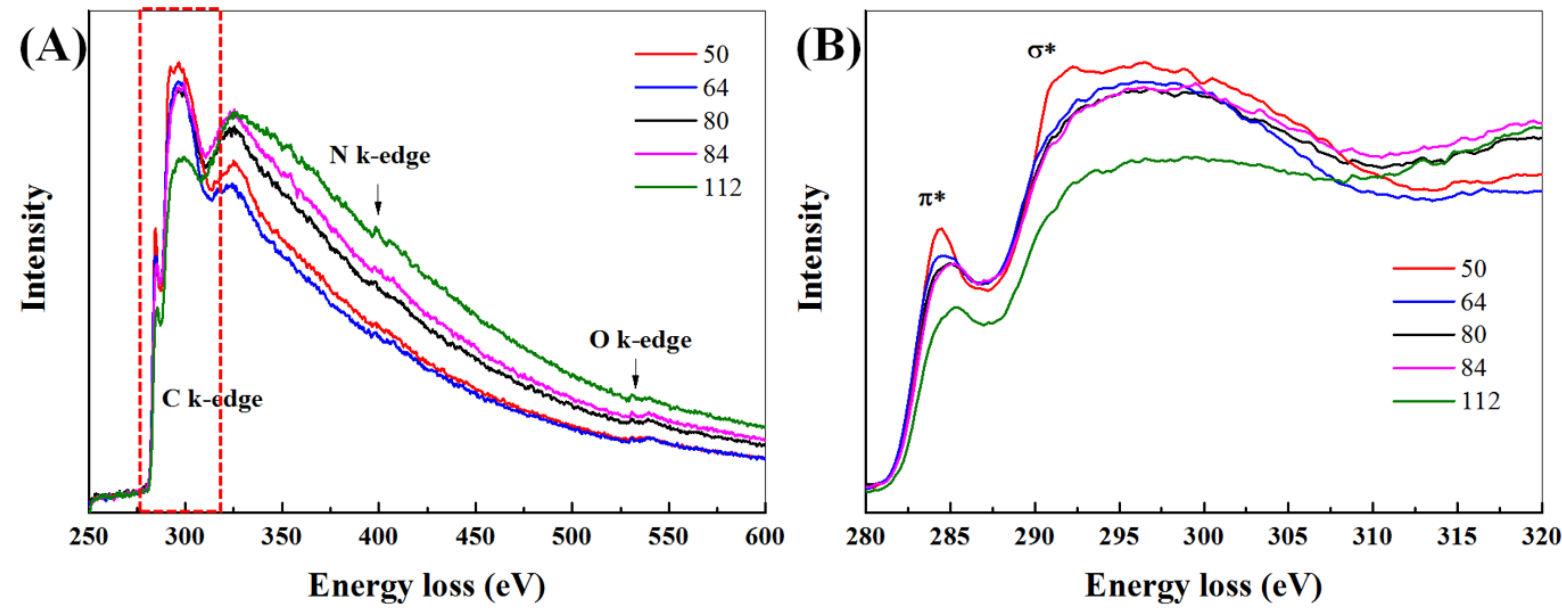

Figure 3 (A) The energy-loss spectra of C K-edge, N K-edge and O-K edge with different sample thicknesses; (B) The enlarged C K-edge marked out in (A).

EELS is effective to obtain fingerprint chemical information (i.e. the electronic structure of atoms, the covalent bonding, and the nearest-neighbor chemical environment) ${ }^{32}$. To study the influence of the thickness on the core-loss spectra, the five spectra were probed at areas marked out 
in Figure 2A with different thickness. In Figure 3A, the individual oxygen peak at approximately 530 eV can be clearly observed for all five spectra with a similar peak intensity ${ }^{33}$. Meanwhile, a clear nitrogen peaks at $400 \mathrm{eV}$ appears for the thicker probed area and gradually decreases with the thickness.

Table 1 The thickness influence on the $\mathrm{O} / \mathrm{C}$ and N/C ratios in the epoxy matrix.

\begin{tabular}{cccccc}
\hline Thickness $(\mathbf{n m})$ & $\mathbf{5 0}$ & $\mathbf{6 4}$ & $\mathbf{8 0}$ & $\mathbf{8 4}$ & $\mathbf{1 1 2}$ \\
\hline O/C ratio $(\%)$ & 8.62 & 6.04 & 7.42 & 10.2 & 10.57 \\
\hline N/C ratio $(\%)$ & 2.32 & 0.78 & 2.28 & 1.69 & 1.10 \\
\hline
\end{tabular}

Although all five spectra were acquired from the pure epoxy matrix, the thickness lead to different intensities of a specific element. Based on this result (as shown in Table 1), a relatively thick area could have a higher inelastic cross-section, which leads to a greater sensitivity to the $\mathrm{N}$ and $\mathrm{O}$ element.

In Figure 3B, the C K-edge spectra of the five probed areas show an energy-loss around $284 \mathrm{eV}$. A clear feature of the peak at $284 \mathrm{eV}$ is attributed to the $\mathrm{C}=\mathrm{C} \pi^{*}$ resonance and the peak at $292 \mathrm{eV}$ is attributed to carbon $\mathrm{sp}^{3}$ bond (C-C $\sigma^{*}$ resonance) ${ }^{34}$. For the $112 \mathrm{~nm}$-thick sample, the spectrum is relatively smooth, few peaks could be distinguished. However, for the thinner $50 \mathrm{~nm}$-thick sample, it is possible to distinguish low-signal peaks. Rosenberg et al. ${ }^{35}$ have reported that those low-signal peaks are not due to noise but correspond to real transitions. Based on this, the thinner sample is more sensitive to the $\mathrm{C} K$-edge.

Based on Ferrari's study ${ }^{36}$, the low loss peak position can be used to evaluate the mass density of the probed area. To analyze different phases in the three composites, low-loss spectra were acquired. Figure 4A shows the HAADF STEM image of a GNP/epoxy composite, in which the bright thin line in the center corresponds to the GNP. Seven spots are analyzed using EELS, the fourth being in the GNP region and the others six points being in the matrix part. The same acquisitions are performed in GO/epoxy matrix on six different spots, in which the fourth and fifth points are in the GO region, as shown in Figure 4B. For GNP-CNT/epoxy composites, since the CNTs have an average thickness of 50-80 nm, a higher magnification is used to ensure that some points were acquired from the CNT region, as shown in Figure 4C. The tubular structure of CNTs could be clearly observed at this magnification. Among the six points chosen in GNP-CNTs/epoxy composites, the first, third and fourth points are probed on the CNT part. The second point is probed on the matrix and the fifth and sixth are probed on the GNP region. 
The low-loss peak values are extracted out from the spectra and their locations represented as shown in Figure 4(D-F) for GNP/epoxy, GO/epoxy and GNP-CNT/epoxy composites, respectively. For all spectra acquired from the three samples, the energy loss is in the range of 22.5-23.6 eV. There is a small variation between them nonetheless, which is quite reasonable since all the components cannot be identical during the crosslinking reaction. However, in the GNP/epoxy composite, the energy-loss corresponding to the GNP region $(26.9 \mathrm{eV})$ is much higher than that in the matrix part. In the GO/epoxy composite, the energy-loss of GOs is in the range of 21.3-21.8 eV, a little lower than that of the matrix. In the hybrid reinforced composite, the CNTs have an energy-loss value of $24.5 \mathrm{eV}$, in between the matrix and the GNP values. However, the energy-loss of the GNP part in the hybrid is even smaller than that of the CNTs, and at the same level as the matrix.

Since GOs, GNPs, CNTs and the matrix are composed of one or several light elements, C, O and $\mathrm{N}$, the weight and valence density of these three elements have a very small discrepancy. Hence, their difference in energy-loss can directly reflect the variation of the mass density. To confirm the experimental results, the mass densities of the GOs, GNPs, CNTs and epoxy are either found from the literature or calculated directly, and give $1.06,2.25{ }^{37}, 2.1$ and $1.13 \mathrm{~g} / \mathrm{cm}^{3}$, respectively. Compared to these values, the energy-losses in GNP/epoxy and GO/epoxy are in a very good agreement with the density results. However, for the CNTs, the energy-loss is smaller than for GNPs. For the GNPCNT/epoxy composite, the specimen thickness is around $100 \mathrm{~nm}$, and is greater than the diameter of the CNTs, in the range of $50-80 \mathrm{~nm}$. Hence, even when the probe is focused on the CNT, the low-loss peak contains a part of the signal of the surrounded matrix (as shown in Figure $\mathbf{5}$ ). The energy-loss is a weighted average value of the CNTs and the matrix. 

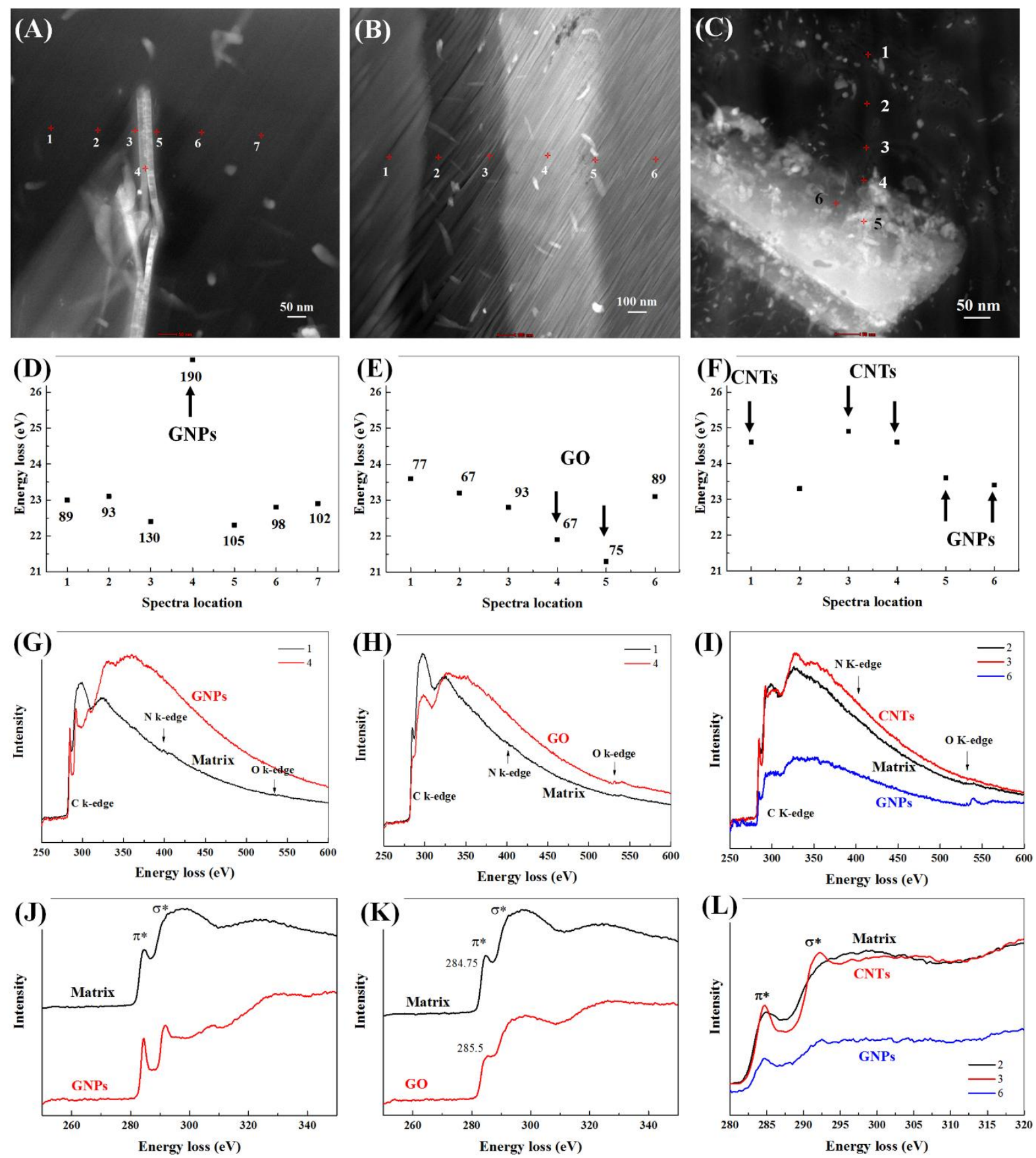

Figure 4 HAADF-STEM images of (A) GNPs/epoxy, (B) GO/epoxy and (C) GNP-CNTs/epoxy. (D-F) Corresponding plasmon peak values. (G-I) Corresponding core-loss spectra. (J-L) Zoom on the C Kedge. 


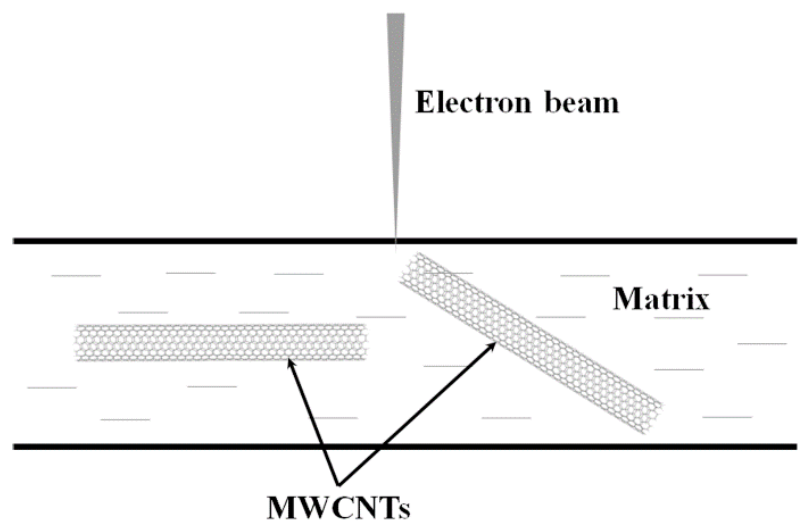

Figure $5 \mathrm{~A}$ scheme of the cross-section of GNP-CNT/epoxy sample where the electron beam pass though the MWCNT region with random orientation.

To confirm the fine structure of the nanofillers and the epoxy matrix, the core-loss spectra have been acquired in the different phases of all three types of composites. Figure $\mathbf{4 G}$ shows the core-loss spectra of the GNPs and epoxy matrix acquired from the first and fourth points in Figure 4A, respectively. The spectra of the matrix are discussed intensively and to make a comparison with the GNPs, the $\mathrm{O}$ K-edge at $530 \mathrm{eV}$ and N K-edge at $400 \mathrm{eV}$ do not appear in the GNP spectrum. The GNPs used here have maintained their composition during the composite fabrication process. Figure $4 \mathbf{J}$ zooms on the C K-edge at $284 \mathrm{eV}$ to study the fine structures. The C K-edge of the matrix is very similar to the amorphous carbon case. However, the C K-edge of GNPs shows two obvious peaks at $284 \mathrm{eV}$ and $292 \mathrm{eV}$, which corresponds to the $1 s$ to $\pi^{*}$ and $1 s$ to $\sigma^{*}$ transitions, respectively. The peak shapes are very similar to graphite, indicating its $s p^{2}$ layered structure. Figure $\mathbf{4 H}$ shows the core-loss spectra of a GO and matrix. The spectra of the epoxy matrix exhibit very few differences from one type of composite to the other. For the GO spectrum, the $\mathrm{O}$ K-edge at $530 \mathrm{eV}$ appears more strongly due to the oxidation process. Figure $\mathbf{4 K}$ shows the enlarged $\mathrm{C} \mathrm{K}$-edge of the matrix and the GO. Few differences could be distinguished from these two spectra, indicating that the GO becomes amorphous after oxidation. For the GNP-CNT/epoxy composite, three core-loss spectra corresponding to the matrix, CNTs and the GNP, have been acquired and shown in Figure 4I. The spectrum of CNTs is a mixed signal of the CNTs and the matrix. The N K-edge and O K-edge are not as strong as in the matrix. However, a very strong O K-edge appears in the GNP spectrum, which indicates that the GNP has been oxidized in the hybrid composites. The C K-edge shown in Figure $\mathbf{4 L}$ has a great difference entre three phases. The CNT C K-edge shows obvious $\pi^{*}$ and $\sigma^{*}$ transition peaks due to its graphitic structure. These two peaks are very weak in the GNP spectrum due to the oxidation. 

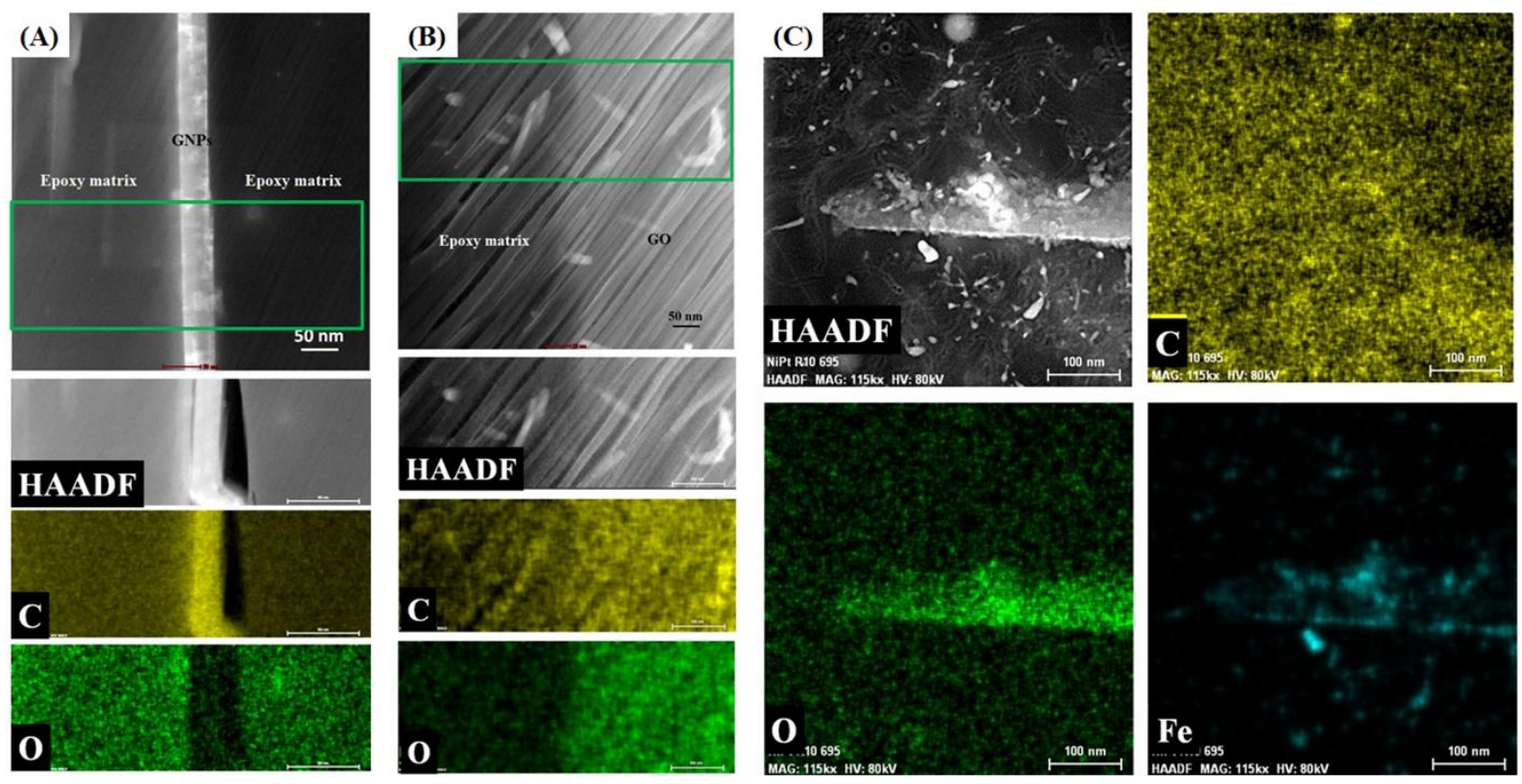

Figure 6 High magnification STEM Z-contrast image showing the nanofillers in the epoxy matrix: (A) GNPs/epoxy, (B) GO/epoxy and (C) GNP-CNTs/epoxy composites, respectively. The regions marked out by green rectangular in $(A)$ and $(B)$ and the entire region in (C) were analyzed by EDX, the elements were marked out by different colors, green for oxygen, yellow for carbon, and blue for iron, respectively.

To further confirm the element distribution in the three composites, energy-dispersive analysis (EDX) mapping was acquired in three composites, as shown in Figure 6. Once the proper threshold applied to transform the spectrum intensity of a given pixel into a colored pixel, the brightness of a given element color represents the relative concentration of this element. Figure $6 \mathrm{~A}$ presents a STEM image of a raw GNP/epoxy composite. The bright region in the center corresponds to the GNP and the two sides with the relatively low brightness correspond to the epoxy matrix. A region in the center has been selected to perform the EDX analysis and two elements, oxygen and carbon, have been analyzed. The HAADF image shows the morphology after EDX acquisition. To obtain a high-resolution mapping, 10 mins have been used to do the acquisition. Some damages were observed afterwards since the polymer matrix is very sensitive to electron irradiation: The interface was broken, which gives an evidence that original GNPs have a weak interaction with epoxy matrix. Since the GNPs contain the carbon element only and have a higher density than the matrix part, carbon is shown with a brighter color in the GNP region than in the matrix. There is no oxygen 
in the GNP part, but a weak signal still exists, due to the FIB milling process which introduces a small amount of oxygen. The oxygen in the GNP domain is much lower than in the matrix.

Figure 6B shows a STEM image of a GO/epoxy composite. After oxidation, GOs have a very similar composition compared to the matrix, which decreases the contrast. The HAADF image shows the state after the acquisition, where the interface is not broken. The oxygen-containing groups in the GO could react with the curing agent in the matrix and build a strong interface. The $\mathrm{C}$ mapping shows very few differences. However, the GOs domain shows a relatively higher concentration of oxygen compared to that of the matrix part. Figure 6C shows the EDX mapping of a GNP-CNT/epoxy composite, where three elements -- carbon, oxygen and ion -- were acquired. The HAADF shows the clear tubular structure of the CNTs, the bright triangle part is the GNP, the bright spots the iron catalyst. The carbon mapping shows very few differences in the region. However, the GNP part has a much higher oxygen concentration than the other parts, which confirms the conclusion made before. The GNPs have been oxidized in the hybrid composite. The iron mapping confirms the presence of the catalyst.

\section{CONCLUSIONS}

In this work, three kinds of composites, GNP/epoxy, GO/epoxy and GNP-CNT/epoxy composites, have been studied. The nanoscale characterization of three composites has been conducted by combining STEM-EELS-EDX observations. The effect of the TEM sample thickness has been investigated. It can be found that the thickness under $120 \mathrm{~nm}$ has a limited effect on the low-loss spectra. However, in a certain range, thicker samples have a better element sensitivity to the $\mathrm{N}$ and O K-edge peaks. Then, the low-loss and core-loss spectra of the four kinds of composites have been studied intensively. The element composition in the different samples could be easily obtained with the core-loss spectra. The density varied in the matrix and nanofiller domains. Finally, an EDX mapping was also conducted in this work, the difference at the interface caused by the surface treatment could be easily observed and could be used to indirectly evaluate the interface strength.

\section{ACKNOWLEDGEMENTS}

This work was carried out within the MATMECA consortium and supported by the ANR under contract number ANR-10-EQPX-37. It has benefited from the facilities of the Laboratory MSSMat (UMR CNRS 8579), CentraleSupélec, France. We thank Dr. L. WANG and Dr. Y. CHEN for the SEM sample preparation. Yu LIU thanks China Scholarship Council for the fellowship. The GNPs used in this paper was purchased by GDR 3661 Polynano. GO was kindly offered by Standard Graphene.

\section{REFERENCES}


1. Balandin, A. A.; Ghosh, S.; Bao, W.; Calizo, I.; Teweldebrhan, D.; Miao, F.; Lau, C. N., Nano letters 8, 9022008.

2. $\quad$ Lee, C.; Wei, X.; Kysar, J. W.; Hone, J., science 321, 3852008.

3. Mayorov, A. S.; Gorbachev, R. V.; Morozov, S. V.; Britnell, L.; Jalil, R.; Ponomarenko, L. A.; Blake, P.; Novoselov, K. S.; Watanabe, K.; Taniguchi, T.; Geim, A. K., Nano Letters 11, 23962011.

4. Wu, X.; Sprinkle, M.; Li, X.; Ming, F.; Berger, C.; de Heer, W. A., Physical Review Letters 101, 0268012008.

5. Liu, Z.; Zhou, X., Graphene: energy storage and conversion applications; CRC Press, 2014.

6. Kuila, T.; Bose, S.; Khanra, P.; Mishra, A. K.; Kim, N. H.; Lee, J. H., Biosensors and Bioelectronics 26, 46372011.

7. Huang, X.; Qi, X.; Boey, F.; Zhang, H., Chemical Society Reviews 41, 6662012.

8. Young, R. J.; Kinloch, I. A.; Gong, L.; Novoselov, K. S., Composites Science and Technology 72, 14592012.

9. Stankovich, S.; Dikin, D. A.; Dommett, G. H.; Kohlhaas, K. M.; Zimney, E. J.; Stach, E. A.; Piner, R. D.; Nguyen, S. T.; Ruoff, R. S., nature 442, 2822006.

10. RamanathanT; Abdala, A. A.; StankovichS; Dikin, D. A.; Herrera Alonso, M.; Piner, R. D.; Adamson, D. H.; Schniepp, H. C.; ChenX; Ruoff, R. S.; Nguyen, S. T.; Aksay, I. A.; Prud'Homme, R. K.; Brinson, L. C., Nat Nano 3, 3272008.

11. Sengupta, R.; Bhattacharya, M.; Bandyopadhyay, S.; Bhowmick, A. K., Progress in Polymer Science 36, 6382011.

12. Kim, H.; Abdala, A. A.; Macosko, C. W., Macromolecules 43, 65152010.

13. Cao, Y.; Zhang, J.; Feng, J.; Wu, P., ACS Nano 5, 59202011.

14. Bai, L.; He, S.; Fruehwirth, J. W.; Stein, A.; Macosko, C. W.; Cheng, X., Journal of Rheology 61, 5752017.

15. Im, H.; Kim, J., Carbon 50, 54292012.

16. Dreyer, D. R.; Park, S.; Bielawski, C. W.; Ruoff, R. S., Chemical Society Reviews 39, 2282010.

17. Khobragade, P. S.; Hansora, D. P.; Naik, J. B.; Njuguna, J.; Mishra, S., Polymer International, n/a.

18. Haeri, S. Z.; Asghari, M.; Ramezanzadeh, B., Progress in Organic Coatings 111, 12017.

19. Li, W.; Dichiara, A.; Bai, J., Composites Science and Technology 74, 2212013.

20. Zhao, H.; Bai, J., ACS Applied Materials \& Interfaces 7, 96522015.

21. Li, W.; Yuan, J.; Lin, Y.; Yao, S.; Ren, Z.; Wang, H.; Wang, M.; Bai, J., Carbon 51, 3552013.

22. Soldano, C.; Mahmood, A.; Dujardin, E., Carbon 48, 21272010.

23. Liu, Y.; Hamon, A.-L.; Haghi-Ashtiani, P.; Reiss, T.; Fan, B.; He, D.; Bai, J., ACS Applied Materials \& Interfaces 8, 341512016.

24. Leyva-Porras, C.; Ornelas-Gutiérrez, C.; Miki-Yoshida, M.; Avila-Vega, Y. I.; Macossay, J.; Bonilla-Cruz, J., Carbon 70, 1642014.

25. Luo, X.; Ma, K.; Jiao, T.; Xing, R.; Zhang, L.; Zhou, J.; Li, B., Nanoscale Research Letters 12, 99 2017.

26. Wu, Q.; Li, M.; Gu, Y.; Li, Y.; Zhang, Z., Composites Part A: Applied Science and Manufacturing 56, 1432014.

27. Malis, T.; Cheng, S. C.; Egerton, R. F., Journal of Electron Microscopy Technique 8, 1931988.

28. lakoubovskii, K.; Mitsuishi, K.; Nakayama, Y.; Furuya, K., Microscopy research and technique $71,6262008$.

29. Erickson, K.; Erni, R.; Lee, Z.; Alem, N.; Gannett, W.; Zettl, A., Advanced Materials 22, 4467 2010.

30. Mkhoyan, K. A.; Contryman, A. W.; Silcox, J.; Stewart, D. A.; Eda, G.; Mattevi, C.; Miller, S.; Chhowalla, M., Nano letters 9, 10582009.

31. Browning, N.; Chisholm, M.; Pennycook, S., Nature 366, 1431993.

32. Egerton, R. F., Electron energy-loss spectroscopy in the electron microscope; Springer Science \& Business Media, 2011.

33. Varlot, K.; Martin, J. M.; Gonbeau, D.; Quet, C., Polymer 40, 56911999. 
34. Kikuma, J.; Tonner, B. P., Journal of Electron Spectroscopy and Related Phenomena 82, 53 1996.

35. Rosenberg, R. A.; Love, P. J.; Rehn, V., Physical Review B 33, 40341986.

36. Ferrari, A. C.; Libassi, A.; Tanner, B. K.; Stolojan, V.; Yuan, J.; Brown, L.; Rodil, S. E.; Kleinsorge, B.; Robertson, J., Physical Review B 62, 110892000.

37. Rafiee, M. A.; Rafiee, J.; Wang, Z.; Song, H.; Yu, Z.-Z.; Koratkar, N., ACS nano 3, 38842009. 